\title{
A 4-year-old child with leukemia and an enlarging arm lesion
}

4-year-old boy was admitAted to hospital with a diagnosis of pre-B-cell acute lymphoblastic leukemia. Ten days later, he experienced fever, neutropenia and a lesion on the lateral aspect of his left arm just above the elbow. The purplish lesion was $1 \mathrm{~cm}$ in diameter and was not painful. The child was given piperacillin and gentamicin, but the lesion increased in size and became necrotic. Ecthyma gangrenosum due to disseminated bacterial infection was initially suspected. However, a skin biopsy revealed wide, aseptate fungal hyphae, consistent with an agent of mucormycosis. The infected site had been under adhesive tape that was used to secure an intravenous catheter, removed sev$\rightarrow$ eral days before, in the antecubital fossa. CT examinations showed that the patient's chest and sinuses were normal, and $\approx$ the child was clinically well. Primary cutaneous mucormycosis . was felt to be the probable diag$\AA$ nosis. Therapy with ampho-

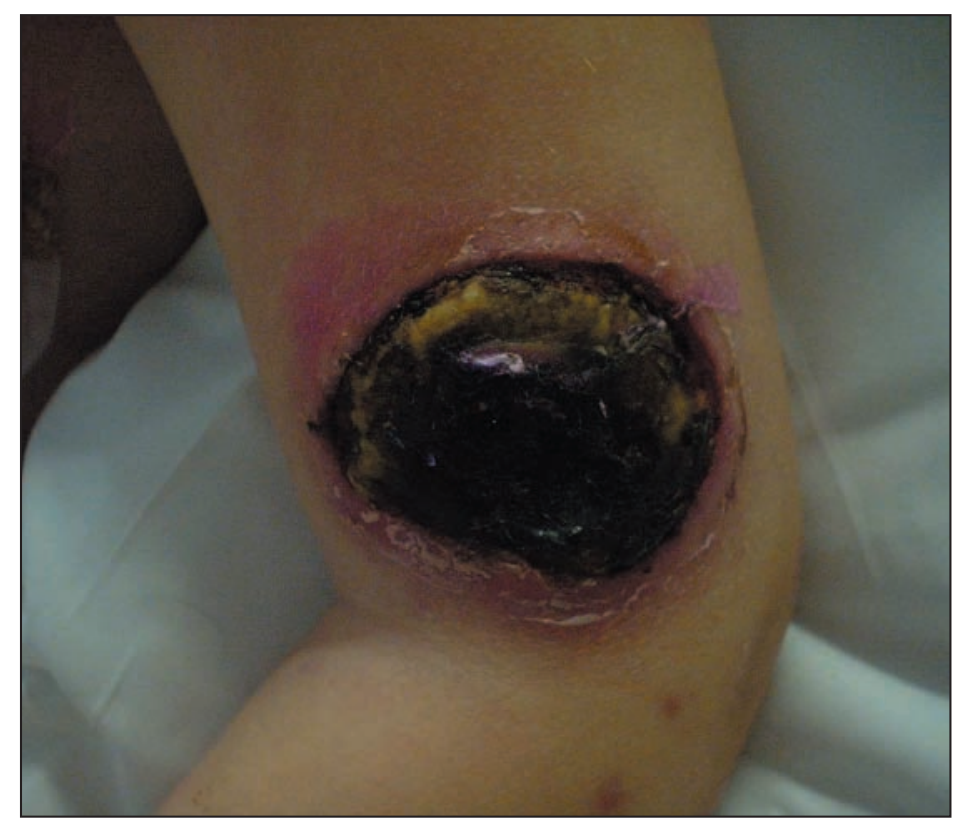

tericin B was started and then changed to $5 \mathrm{mg} / \mathrm{kg}$ of amphotericin B lipid complex per day because of renal impairment. The lesion, which had continued to enlarge, was fully excised. The day before excision, the necrotic area had reached $4.2 \times$ $5 \mathrm{~cm}$ (Fig. 1).

Although the results of the first biopsy were negative, the culture from the excised lesion grew Rhizopus oryzae, a Mucorales fungus. Pathologic examination of the débrided specimen showed necrotic epidermis, dermis and subcutaneous tissue with ischemic necrosis of the blood vessels. The child continued to receive amphotericin $\mathrm{B}$ lipid complex for 6 weeks, and the wound healed steadily over the next 14 weeks. Four months later, no infection had recurred.

The term mucormycosis (or zygomycosis) refers to invasive fungal disease caused by members of the order Mucorales. ${ }^{1,2}$ These fungi have wide nonsep- tated hyphae that may branch at right angles. Infections generally occur in immunocompromised patients with conditions such as neutropenia, diabetes or hematologic malignant disease. ${ }^{1,3}$

Clinical manifestations may be classified as rhinocerebral, pulmonary, gastrointestinal, cutaneous or disseminated. ${ }^{1} \mathrm{Al}$ though this child's lesion may have arisen because of hematogenous dissemination of the fungus, his remarkably good clinical course, the absence of infection at other sites and the location of the lesion at a site where tape had been applied suggest this was a primary cutaneous infection.

Cutaneous mucormycosis usually occurs after skin trauma and has been described following minor trauma caused by adhesive tape or dressings. ${ }^{3,4}$ Treatment includes wide surgical excision and antifungal therapy with amphotericin $\mathrm{B}$.

\section{Ahmed Mater}

Ghada Al-Sulaiti

Donna L. Johnston

Robert Slinger

Departments of Pediatrics and of

Laboratory Medicine and Pathology

Children's Hospital of Eastern

Ontario

University of Ottawa

Ottawa, Ont.

\section{References}

1. Prabhu RM, Patel R. Mucormycosis and entomophthoramycosis: a review of the clinical manifestations, diagnosis and treatment. Clin Microbiol Infect 2004;10(Suppl 1):31-47.

2. Adam RD, Hunter G, DiTomasso J, Comerci G Jr. Mucormycosis: emerging prominence of cutaneous infections. Clin Infect Dis 1994;19(1):67-76.

3. Boyd AS, Wiser B, Sams HH, King LE. Gangrenous cutaneous mucormycosis in a child with a solid organ transplant: a case report and review of the literature. Pediatr Derm 2003;20:411-5.

4. Alsuwaida K. Primary cutaneous mucormycosis complicating the use of adhesive tape to secure the endotracheal tube. Can 7 Anaesth 2002;49:880-2. 